\title{
Diagnosis and treatment of hysterical conversion reactions
}

\author{
S A LESLIE \\ Department of Child and Family Psychiatry, Booth Hall Children's Hospital, Manchester
}

SUMMARY Twenty children with hysterical conversion reactions were reviewed. The ways in which they became ill, the attitudes of their families to their illnesses and their underlying personal problems were noted. Treatment comprised avoiding unnecessary investigations and removing symptoms by using graded exercises given by physiotherapists. Exploration of the underlying psychological problems took place at a pace with which the family could cope because many families were reluctant at first to accept that the illness was psychological.

Seventeen of the 20 children recovered completely within three months of starting treatment. The results show that early diagnosis and close liaison between paediatricians, physiotherapists, and child psychiatrists are necessary if prolonged handicap is to be avoided.

Hysterical conversion reactions are not common in the United Kingdom ${ }^{1}$ being diagnosed in between $0 \cdot 5-1 \%$ of referrals to a child psychiatric inpatient centre $^{23}$ and $1 \%$ of referrals to adult neurological units. ${ }^{4}$ The prevalence in paediatric practice is not known. When they do arise, however, they present serious problems of management for the clinician who is anxious about missing organic disease ${ }^{56}$ but aware of the danger of prolonging the children's disabilities by unnecessary investigations. ${ }^{7}$ Many families with such children seem to be resistant to the possibility that a psychological problem exists and clumsy interventions may only result in the families seeking other opinions-events that may cause the clinicians to agree with the families that further tests may be necessary.

The studies of Goodyer, ${ }^{2}$ Caplan, ${ }^{3}$ and Rock $^{8}$ defined the condition precisely: 'prominent somatic symptoms with a disturbance of the central nervous system or of limb dysfunction whose investigation by a specialist unit has failed to establish any anatomical or physiological basis for the complaint'. All three authors stressed the need to make a psychiatric diagnosis. Making such a diagnosis, however, is not always easy given the resistance of some children and their families to intervention by a psychiatrist. Children may fear the loss of the sick role and may go to extreme lengths to persuade their parents and their doctors that they are ill.

The concepts of the 'sick role' and illness behaviour have been helpful in our reappraisal of hysterical conversion reactions and conversion reactions are now treated as different from hysterical personalities and hypochondria, or Briquet's syndrome, described by Kendall. ${ }^{9}$ Taylor argued that for a hysterical reaction to develop, the patient had to be in a predicament from which all other avenues were blocked, and that the patient had an ally who helped to promote the sickness; this was either a member of the family or the doctor. ${ }^{10}$ Furthermore the patient was usually copying someone (whether current or historical) and hysteria had to be enacted by a person with sufficient social skills. Hence it does not occur in very young children.

Psychological intervention must begin by searching for the importance the illness has for the children, and what they hope to gain by remaining ill; ${ }^{11}$ this underlying motivation may or may not be conscious.

\section{Patients and methods}

Twenty six children with hysterical conversion disorder ${ }^{12}$ seen consecutively in the department of child psychiatry during a three and a half year period in 1983-7 were studied. Six children who had presented with pseudo fits were excluded from the study because their behaviour was episodic and required a different treatment regimen. The remaining 20 children had all been examined and investigated in units specialising in neurology, paediatrics, or orthopaedics, to which they had presented with functional disorders of the central nervous system for which no organic cause could be found. 
Psychiatric evaluation of the children included enquiries about recent stresses at home, at school, and with their friends, and possible reasons for remaining ill. Many of the case notes gave verbatim comments on the children's attitudes to life.

The aims of treatment and assessment were: to stop further physical investigations and explain the reasons for this in conjunction with the referring specialist and if possible the family doctor; to show that complete recovery was possible with the help of 'face saving' treatment given by a skilled and understanding physiotherapist; and to move towards psychological treatment at a pace which the children and families could accept. ${ }^{7}$

\section{Results}

Thirteen girls and seven boys (a ratio of about 2:1) with a mean age of 13 (range 11-15) were diagnosed as having hysterical conversion disorders during the period late $1983-$ early 1987 , nearly $2 \%$ of the total number of children seen $(n=1090)$.

\section{PRESENTING SYMPTOMS}

Table I shows the symptoms with which the children presented, weakness of the legs accompanied by a bizarre gait being the most common. This

Table 1 Presenting complaints of 20 children with hysterical conversion reactions

\begin{tabular}{lllr}
\hline Disability & $\begin{array}{l}\text { No of } \\
\text { girls }\end{array}$ & $\begin{array}{l}\text { No of } \\
\text { boys }\end{array}$ & Total \\
\hline $\begin{array}{l}\text { Weakness of legs and bizarre } \\
\quad \text { gait }\end{array}$ & 5 & 5 & 10 \\
Inability to move & 2 & 1 & 3 \\
Foot drop & 2 & 1 & 3 \\
Weakness of arm & 2 & - & 2 \\
Contracture of toes & 1 & - & 1 \\
Torticollis & 1 & - & 1 \\
Total & 13 & 7 & 20 \\
\hline
\end{tabular}

often meant that the children clung desparately to someone else or moved with great difficulty with crutches. The abnormality of gait was not suggestive of organic disease.

Three children were almost totally incapacitated, one could not bear to sit or stand, and one was apparently so disabled he had to be fed by his mother. Another was confined to a wheel chair, unable to feed herself or go to the toilet without assistance. The child with torticollis had had her neck in the same position for a year and the child with contracture of the toes had maintained the same position for seven months, though the foot relaxed when she was asleep. Nearly all the children complained of pain in the affected areas. Few of the children behaved as if they were concerned about their symptoms, although their parents certainly were.

\section{DURATION OF SYMPTOMS BEFORE REFERRAL TO A PSYCHIATRIST}

Twelve of the children had had their symptoms for over three months and five for more than a year. Only two had had symptoms for less than a month (table 2). Most had considerably reduced their activities often entailing time off school and disruption of family life. All the children had been seen by specialists; none had been referred directly to the child psychiatrist by the family doctor or school medical officer. Thirteen were referred by paediatric neurologists, four by paediatricians, and three by orthopaedic surgeons.

Only four children had seen a single specialist, eight children had seen two specialists, and four had seen three specialists. Three children, all of whom had had symptoms for over a year, had seen four specialists (usually seeking private opinions).

\section{ATTITUDE TO THE CHILD'S ILLNESS}

A pronounced feature was the anger of many of the families about what they saw as the failure of the medical profession to diagnose or to treat their

Table 2 Outcome of treatment in 20 children with hysterical conversion reactions

\begin{tabular}{lcccc}
\hline Duration of symptoms & No of patients & \multicolumn{2}{l}{ Time taken to recover function } \\
\cline { 3 - 4 } & & $<1$ Month & $>1$ Month but & $>3$ Months \\
& & & 0 & 0 \\
\hline 1 Month & 2 & 2 & 3 & 0 \\
$>1$ Month but $<3$ months & 6 & 3 & 1 & 1 \\
$>3$ Months but $<6$ months & 6 & 0 & 0 & 2 \\
$>6$ Months but $<1$ year & 1 & 3 & 0 & 3 \\
$>1$ Year & 5 & 13 & 4 & (partial) \\
Total & 20 & 0 & \\
\hline
\end{tabular}


child's illness properly. Table 3 gives examples of statements made by the parents about the doctors they had seen in the past. The reasons for this hostility often lay in the families' previous history but they could have also been enhanced by insensitive or inadequate handling of the initial complaint.

\section{ASSOCIATED ORGANIC DISEASE}

Most of the children had had a minor illness or accident at the onset of their symptoms though it was not always easy to assess the importance of this in retrospect. Physical trauma was given as the reason for the onset of the symptoms by seven children, and a viral illness by four. Two children. had associated osteochondritis but this was not thought to be responsible for their symptoms.

There was someone for the child to copy in at least seven of the families-for example, one girl who progressed from backache to total immobility had a grandfather who had had been operated on for a slipped disc. Another girl presented with weakness of the legs, and her father had back pain for which he felt he had not been treated satisfactorily.

\section{PARENTAL PSYCHIATRIC ILLNESS}

The parents of five of the children had had psychiatric illnesses in the past that had been of sufficient severity to have been temporarily incapacitated, and two of them had seen a psychiatrist. Three parents had had anxiety states and one

Table 3 Twelve typical examples of parents' reactions

Mother: ". . . felt that fractured toe was not $x$ rayed soon enough."

Parents: ". . . felt plaster put on in casualty did not fit. Previous dissatisfaction with hospital treatment when child was a baby."

Father: "Almost every medical opinion we have had has proved to be wrong."

Parents: "They treated us as if we were stupid." Parents had sought" different opinions-mainly privately.

Mother: "They gave me to understand she might have had a brain haemorrhage." Mother lacked confidence in medical opinion.

Father: Wanted to sue school for negligence about injury at hockey.

Mother: Would not believe doctors' opinion that there was no organic disease. Previous cot death.

Parents: "No-one told us osteochondritis was self-limiting! We had too many different opinions."

Grandfather who had had disc surgery felt no-one outside S- - - Royal Infirmary was any good.

General practitioner prescribed penicillin. "He should know he is allergic to it."

"His TB test was positive, they started him on tablets." False result.

Parents: Very dissatisfied with initial treatment. "They did not $x$ ray his knee." father was having psychiatric treatment for endogenous depression at the time of his daughter's referral. Two of the mothers had suffered from agoraphobia.

It was not possible to ascertain more precisely how anxious the parents were at the time of referral though the mothers' anxious behaviour was often commented on, especially by nursing staff.

\section{HISTORY OF PREVIOUS 'PSYCHOSOMATIC ILLNESS'} IN CHILDREN

Five girls and one boy had previous histories of nonspecific aches and pains which were thought to have been of psychological origin.

More strikingly, six of the seven boys and eight of the 13 girls had no such history and their parents thought they would be unlikely to make a fuss about illness or to have psychological problems, hence their difficulty in accepting the psychological nature of the presenting complaint. None of the children had ever been referred to a child psychiatrist or child guidance clinic previously.

PSYCHIATRIC ASSESSMENT OF THE CHILD

Psychiatric assessment of the children was not always easy because of the resistance of either the children or the families, or both, to the idea of the problem being psychological. They were also concerned about the stigma of being referred to a psychiatrist. It was essential for the referring specialist to explain to each family why referral to a psychiatrist was important, and it was for this reason that we usually saw the most severe cases, as well as those who had already been admitted, on the paediatric ward, for the first consultation.

Parents and child were usually seen separately though family interviews sometimes formed part of the treatment. Though 'saving face' was part of the treatment, we felt it was both unwise and dishonest to disguise the identity of the psychiatrist. The children were told that sometimes worries and problems of which they may or may not have been aware, played tricks on the body and stopped it getting better as quickly as it should. Our job as child psychiatrists was to find out if they might have any such problems.

Our aim was to win the confidence of each child gradually, and to counsel nursing staff and parents that an attitude in which the child was accused of 'putting it on' would increase resistance to treatment. Occasionally a play therapist treated the child.

Usually the children together with their parents began to discuss areas of difficulty during a series of interviews and for the sake of simplicity these are divided into the following three categories: (i) 
problems within the family-that is problems of parental disharmony, sexual abuse, or feeling ignored by preoccupied parents; (ii) problems concerned with peer groups - that is feeling bullied and intimidated, or feeling friendless; and (iii) problems concerned with school work - that is feeling unable to cope, working too hard, or having specific reading or spelling difficulties, or both. Five children had serious problems in more than one category.

\section{Problems within the family}

Families were considered 'disharmonious' when the parents freely admitted to stress that resulted in an atmosphere of tension and mutual recrimination that could be sensed by the children. Four families came into this category. One girl whose parents were separated was afraid of her father's violence when he came to take her out. Of the two girls who eventually admitted that they were being sexually abused, one had been abused by her 28 year old brother who was still living with the family and the other had been abused by a close friend of her father's. Neither had sufficient evidence of physical abuse to convict the offenders, nor had they felt able to confide in their parents. One boy felt his parents were too preoccupied to attend to his needs.

\section{Problems concerned with peer groups}

Four of the seven boys and four of the 13 girls admitted to problems concerned with their peer groups. The boys were concerned about bullying

Table 4 Statements about educational pressures made by or about children

Patient: "I'm not clever, I can't really cope". IQ 100. Child attending independent grammar school with high academic standards.

Patient: 'Daddy won't mind as long as I'm above average." Father late university entrant.

Mother: "She sets very high standards for herself." She had typed solidly for three days.

Mother: "She presses herself, she wants to be top."

Patient: "I feel guilty if I don't get everything right."

Mother: "She's a perfectionist."

Patient: "I can never catch up." (Academically or physically). Family described themselves as fitness fanatics, child had osteochondritis.

Patient: "I worry about getting everything right."

Mother: said child had specific reading difficulties but will not admit it. Plays truant.

Brother: "He has to be top in everything and be first in all his races."

Mother: "He works seven hours a night, he wants to be a doctor to please his grandmother." Child had specific reading difficulties. and issues of sexual identity whereas the girls usually complained of losing friends or feeling excluded from the group because they felt different-for example, being too tall, too fat, or having the wrong accent.

\section{Problems concerning school}

Ten of the 20 children felt under pressure to achieve or push themselves unnecessarily. As academic pressure is a subjective thing, and as many of the children were achieving a great deal, statements made by them or by their parents are listed in table 4 .

Most of the children seemed remarkably unconcerned about the. importance of their symptomsthat is whether they were going to get better or not, but four children had moderate to severe anxiety states, two had mixed disorders of anxiety and depression, and three became clinically depressed, albeit for brief periods, after the diagnosis had been made. Two of these were the girls who had been sexually abused. Indifference was not therefore a totally reliable feature.

\section{TREATMENT}

Treatment was aimed at moving the emphasis from the physical to the psychological aspect of the illness at a pace with which the family could cope. For those children who had already seen several specialists, a further stay in the paediatric ward was often recommended after the child psychiatrist had become involved. This was partly to give time for the family to develop confidence in the psychiatric team and partly (with the aid of the physiotherapists) to show that the children were recovering. We suggested to some of the children that it would not be right for them to go home before they were completely better. This was an effective technique if we could be sure that the child, though reluctant to stop faking illness, was even more reluctant to remain in hospital indefinitely. Weekend leaves were allowed as long as progress was being made in physiotherapy.

Three children were admitted to the psychiatric unit and some of the children treated on the paediatric ward attended the psychiatric unit day school. Six children were treated as outpatients. Psychological treatment depended on the problem underlying the symptom but was usually mainly supportive, occasionally bringing in the whole family.

\section{OUTCOME}

Thirteen of the 20 children recovered from their physical symptoms within one month of the start of treatment, and 17 had recovered within three months. Of the three who took longer all were girls 
and all had had their symptoms for more than six months. They had all begun with minor trauma and not viral illnesses. Two recovered completely during the next 12 months. The girl with contracture of the toes still had some flexion deformity at the time of writing, but she had no contractures and could wear ordinary shoes. She was mildly handicapped.

Two families withdrew from treatment before the psychological problems had been fully addressed, and two were referred to child psychiatric services nearer their homes, but failed to proceed with treatment. At the time of writing the children had had no recurrence of their physical symptoms. One girl who alleged that she had been sexually abused by her 28 year old brother recovered from her physical symptoms and went to live with her sister under the supervision of the social services department. At the age of 17 (when her brother had gone to live abroad) she returned home and later that year was knocked down by a car and killed.

\section{Discussion}

Hysterical conversion disorders, though puzzling to the clinician and a challenge to the psychiatrist, are quite rare. The group studied represented about $2 \%$ of all referrals to the child psychiatric department at a hospital that takes referrals to the neurological department from the whole region. It is similar to other studies in the strict diagnostic criteria used, including those children who were treated as outpatients. The ratio of girls to boys of $2: 1$ was as expected $^{2}{ }^{3}$.

Treatment was similar to that advocated by Dubowitz and Hersov ${ }^{7}$ but occasionally we used a paradoxical technique of recommending treatment in hospital in selected cases until the children had recovered. We felt that this gave the physiotherapist a more effective part in encouraging them to get better. It also showed the parents that the children were improving, and helped us to gain their trust.

One of the greatest difficulties for the psychiatrist when asked to see these children was to decide whether there was a psychiatric disorder, and this difficulty was made worse when there was resistance and sometimes active hostility from the parents, and when the child denied that there were problems. Though most of the children were eventually found to have difficulties in their lives, these were not always obvious at the first interview. ${ }^{13}$

An important observation in this series is that no child was under the age of 11 years. This supports Taylor's observation that children must have the necessary social skills to fake illness and the diagnosis should therefore rarely be considered in very young children. ${ }^{3} 10$
Taylor also proposed that in children sickness is promoted by an 'ally' who may be a member of the family who continues to believe that the child is physically ill despite evidence to the contrary, or it may be the doctor who continues to investigate unnecessarily. It was apparent in the group studied that several of the families were angry at what they saw as the incompetence or inadequacy of their doctors, and this often had its roots in the family's past experience. This attitude itself may force doctors to investigate and even operate against their better judgment, and in three cases comments were made to that effect by consultants. General practitioners should be in a position to advise families not to go from specialist to specialist and have the condition investigated over and over again, but with some of these families this would have been hard to resist.

The children's problems started in different ways. Many of them had had minor illnesses or accidents from which they failed to recover. Without these it is possible that some of them may not have developed the reactions at all but others may have expressed their distress in different ways. Conversely, the degree of apparent disability did not readily relate to the severity of the problems the children were experiencing. It may be that the combination of several factors was necessary to produce the reaction, namely the initial experience of feeling unwell, a personal predicament that was difficult to talk about but that may or may not have been serious, the social skill to fake the illness, and the attitude of the families towards the children's conditions. The response of the doctors could then be contributory. Once the children had stated they were ill it could have been difficult to escape without loss of face.

The problems that the children had were those of children with emotional disorders-that is, anxieties about school, friendships, and their parents. ${ }^{3}$ Only one of the children had any behaviour problem and he had played truant from school because of reading difficulties; he was described as sensitive and anxious. An interesting finding, however, was the extreme conscientiousness not to say perfectionism of at least half of the children, and it was this characteristic which could have led paediatricians to agree with the families that such exemplary children who were doing so well academically and socially and who had had no previous psychiatric histories could not possibly have had psychiatric problems. Academic stress has been noted previously as an underlying problem in childhood hysteria. ${ }^{14}$ Moreover it is these children who may be unable to admit that they have any problems. Sexual abuse is of course another predicament that is often difficult to talk about. 
The follow up has been concentrated on the children's physical recovery, but confirms other studies. ${ }^{2} 7$ More detailed psychiatric follow up is, however, necessary, particularly in the longer term.

This report highlights the benefit of a vigorous, multidisciplinary therapeutic programme which takes into account the parents' anxieties, the children's need for a 'face saving' escape, and an opportunity to discuss emotionally charged issues in a way that was not possible hitherto.

I thank Dr Elena Garralda for permission to report four of her patients and for her helpful comments in the presentation of this paper, and Miss Sue Almond, senior physiotherapist, for her invaluable assistance.

\section{References}

${ }^{1}$ Creak M. Hysteria in childhood. Acta Paedopsychiatrica 1969; 36:264.

2 Goodyer I. Hysterical conversion reactions in childhood. J Child Psychol Psychiatry 1981;22:179-88.

3 Caplan HL. Hysterical conversion symptoms in childhood. London: University of London, 1970. (Dissertation.)
${ }^{4}$ Marsden CD. Hysteria-a neurologists view. Psychol Med 1986;16:277-88.

${ }^{5}$ Slater E. Diagnosis of hysteria. Br Med J 1965;i:1395-9.

6 Rivinus TM, Jamison DL, Graham PJ. Childhood organic neurological disease presenting as psychiatric disorder. Arch Dis Child 1975;50:115-9.

${ }^{7}$ Dubowitz V, Hersov L. Management of children with nonorganic (hysterical) disorders of motor function. Dev Med Child Neurol 1976;18:358-68.

8 Rock NL. Conversion reactions in childhood. J Am Acad Child Psychiatry 1971;10:65-93.

9 Kendall RE. A new look at hysteria. Medicine 1972;30:1780-3.

10 Taylor DC. Hysteria, play acting and courage. Br J Psychiatry 1986;149:37-41.

11 Laybourne PC, Churchill SW. Symptom discouragement in treating hysterical reactions of childhood. International Journal of Child Psychotherapy 1972;1:111-4.

12 World Health Organisation. International classification of diseases. 9th revision. Geneva: WHO, 1978.

13 Goodyer I, Taylor DC. Hysteria. Arch Dis Child 1985;60:680-7.

14 Volkmar FR, Poll J, Lewis M. Conversion reactions in childhood and adolescence. J Am Acad Child Psychiatry 1984;23: 424-30.

Correspondence to Dr S A Leslie, Department of Child and Family Psychiatry, Booth Hall Children's Hospital, Blackley, Manchester M9 2AA.

Accepted 7 December 1987 